\title{
Very-High-Speed Miniaturized Permanent Magnet Motors: Modeling and Experimental Validation
}

\author{
Guillaume Burnand and Yves Perriard, Senior IEEE \\ Integrated Actuators Laboratory (LAI) \\ École Polytechnique Fédérale de Lausanne (EPFL) \\ Switzerland \\ guillaume.burnand@epfl.ch
}

\begin{abstract}
The purpose of this paper is to present an experimental method to separate losses components due to the rotation of the rotor in very-high-speed permanent magnet machines with ball bearings. In addition, it presents and validates an analytical model for the computation of induced eddy current losses in rectangular section conductors due to a rotating magnetic field. It also validates an empirical windage losses model. The measurements are performed on a very-high-speed miniaturized permanent magnet motor up to $400 \mathrm{krpm}$. To the authors' knowledge it is one of the smallest and fastest electrical motor ever operated.
\end{abstract}

Index Terms-Very-high-speed motor, synchronous motor, miniaturized motor, permanent magnet, losses modeling, experimental validation.

\section{INTRODUCTION}

More and more very-high-speed (VHS) applications are used in research and industry, such as pumps, fans, gas turbines, turbochargers, compressors, machine tools, drills for dental and medical applications or even flywheels for energy storage [1], [2]. There is clearly a tendency to increase the rotational speed of electrical machines. It is justified by the fact that, for a given power, the size of the machine can be diminished, miniaturizing the device, increasing the power density and lowering the weight.

The drawback is the severe strain on VHS machines from a thermal and mechanical point of view. One of the most limiting and critical aspect is the maximal mechanical stress supported by the rotor, especially the permanent magnet (PM) [3]. Also, bearings, with or without contact, are crucial elements. Indeed, they act on the lifespan, the accuracy of the position, the damping, the stiffness and can limit the maximal speed and operating temperature.

Minimization of losses related to high electrical frequency and very-high rotational speed is one of the most important challenges when designing VHS machines. Therefore, the determination of accurate losses models is of the upmost importance. This is particularly true for the windage losses model. Indeed, many empirical models exist, but they all give various estimation of the losses. Thereby, using one of them without pre-validation is uncertain [4]. Some losses models are preferably obtained by measurements, like ball bearing losses or iron losses. Indeed, the first ones are very complex to model, especially at very-high speed. Whereas the second ones seldom correspond to what is given by manufacturers [5].
In [6], measurements are performed, using a deceleration test, on a $500 \mathrm{krpm}$ machine. But the authors were not able to separate losses components, especially ball bearing losses. No others VHS miniaturized motors have been found in the literature at the time of writing this paper.

Similarly in [7] and [8], an approach for the modeling and the experimental validation of a $100 \mathrm{krpm}$ bearingless motor is investigated. However, it is very complicated for bearingless motors to perform deceleration tests in order to measure losses. In fact, it cannot be guaranteed that the bearing control would not generate a breaking torque. In [9], the sum of all theoretical losses components of 4 bearingless prototypes are compared with the measurements of the total losses. Hence, the different losses models could not be validated separately. The same applies in [10] to a $150 \mathrm{krpm}$ bearingless motor.

In the present paper, a $400 \mathrm{krpm}$ one-half inch diameter prototype has been designed and built as pictured in Fig. 1. Information about the construction of the prototype are given in Section II. To the authors' knowledge it is one of the smallest and fastest electrical motor ever operated. Typical applications for such a motor are for medical and dental surgery or for micro gas turbines.

Section III focuses on the mechanical and electromagnetic models used for the design. In particular, a new model for the computation of induced eddy current losses due to the rotation of the PM in rectangular section wires is presented. Finally, an experimental method to isolate every losses component due to the rotation of the rotor is proposed and tested on the prototype in Section IV. This allows to validate the proposed models and to include them in an optimization process to further obtain a new design with lower losses [11]. The losses components due to the rotation are:

- Windage losses

- Ball bearing losses

- Winding losses due to the PM

- Iron losses due to the PM

Unfortunately, the prototype could not be operated on load. Nevertheless, the majority of losses are speed dependant, not current dependant in PM slotless VHS machines. The measurements focus on the motor itself. They do not consider power electronic losses as they depend on the power converter and its control strategy. 


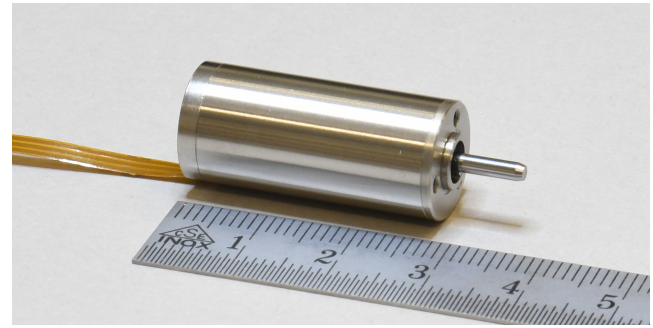

Fig. 1: The one-half inch diameter prototype.

\section{PROTOTYPE CONSTRUCTION}

The outer dimensions of this miniaturized motor are 0.5 inch in diameter $(12.7 \mathrm{~mm})$ and $28 \mathrm{~mm}$ in length. A crosssection of the motor is given in Fig. 2, its inner dimensions and parameters are given in Table I. The rotor has been designed to withstand a $500 \mathrm{krpm}$ rotational speed [3]. The one-piece permanent magnet is made of $\mathrm{NdFeB}$ and its enclosure is in titanium grade 5 . The rotor is supported by ball bearings.

Slotless stators are more appropriated to VHS machines because they reduce the eddy current losses in the PM and the enclosure since there are no slotting harmonics [12]. Moreover, they are easier to construct, especially for miniaturized motors. The stator is made of Metglas ${ }^{\circledR}$ 2605SA1, which has very-low losses at high frequency.

The 3-coil winding is made of rectangular wires. Usually, Litz-wire are preferred in VHS electrical machines because they have less skin and proximity effect losses and less eddy current losses due to the rotation of the PM [13]. However, coils made of Litz-wire are not easy to manufacture, especially for small motors. Rectangular section wires have more eddy current losses but conversely a better radial thermal conductivity, a better filling factor and lower Joule losses [14].

\section{MODELING}

\section{A. Back EMF constant}

For a one pole pair diametrically magnetized cylindrical PM slotless machine, the axial component of the vector potential in the airgap [15] can be computed as

$$
A_{\delta z}(r, \varphi)=c_{\delta}\left(r+\frac{r_{y i}^{2}}{r}\right) \sin (\varphi-\theta),
$$

with $\theta$ being the rotor mechanical angle chosen to be the same as the magnetization angle of the PM, as given by the referential in Fig. 2, and

$$
c_{\delta}=\frac{B_{r} r_{m o}^{2}\left(r_{m i}^{2}-r_{m o}^{2}\right)}{\mu_{r}\left(r_{m i}^{2}+r_{m o}^{2}\right)\left(r_{m o}^{2}-r_{y i}^{2}\right)+\left(r_{m i}^{2}-r_{m o}^{2}\right)\left(r_{m o}^{2}+r_{y i}^{2}\right)},
$$

is a constant depending on the geometry and the properties of the PM (Table I). With $\Gamma$ being the path in the center of the wire, given a purely sinusoidal magnetic field in the airgap and choosing $\theta$ which gives the peak flux in a coil, the back EMF constant for a delta connection is worth

$$
k_{e}=\frac{\sqrt{2}}{2} \oint_{\partial \Gamma} \vec{A} \cdot \overrightarrow{\mathrm{d} l} \text {. }
$$

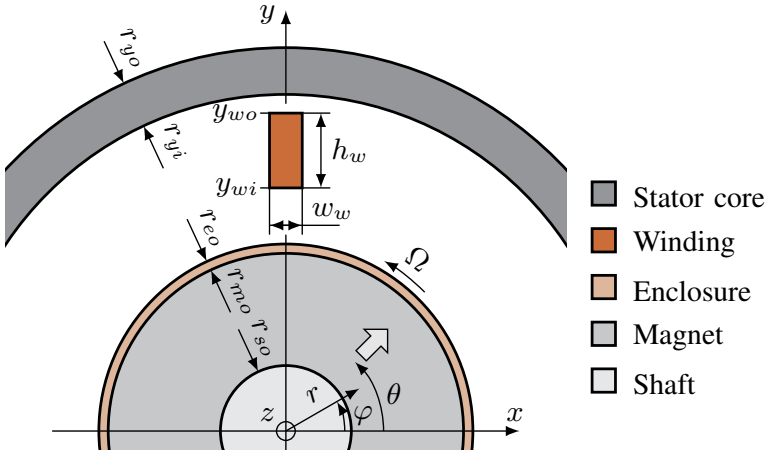

Fig. 2: Prototype cross-section with only one wire highlighted.

TABLE I: PARAMETERS AND DIMENSIONS

\begin{tabular}{lccc}
\hline \multicolumn{4}{c}{ Parameters } \\
\hline PM remanence & $B_{r}$ & 1.13 & {$[\mathrm{~T}]$} \\
PM permeability & $\mu_{r}$ & 1.05 & {$[-]$} \\
Coil resistivity & $\rho_{w}$ & $18.7 \mathrm{e}-9$ & {$[\Omega \mathrm{m}]$} \\
Number of turns per coil & $N_{t}$ & 29 & {$[-]$} \\
Rotor inertia & $J$ & $14.3 \mathrm{e}-9$ & {$\left[\mathrm{~kg} \mathrm{~m}^{2}\right]$} \\
Stator stacking factor & $k_{f}$ & 0.82 & {$[-]$} \\
\hline \multicolumn{4}{c}{ Dimensions } \\
\hline Outer shaft radius & $r_{s o}$ & 1.0 & {$[\mathrm{~mm}]$} \\
Outer magnet radius & $r_{m o}$ & 2.75 & {$[\mathrm{~mm}]$} \\
Outer enclosure radius & $r_{e o}$ & 2.95 & {$[\mathrm{~mm}]$} \\
Inner yoke radius & $r_{y i}$ & 4.5 & {$[\mathrm{~mm}]$} \\
Outer yoke radius & $r_{y o}$ & 5.9 & {$[\mathrm{~mm}]$} \\
Inner wire distance & $y_{w i}$ & 3.3 & {$[\mathrm{~mm}]$} \\
Outer wire distance & $y_{w o}$ & 4.2 & {$[\mathrm{~mm}]$} \\
Wire width & $w_{w}$ & 70 & {$[\mu \mathrm{m}]$} \\
Wire height & $h_{w}$ & 0.9 & {$[\mathrm{~mm}]$} \\
PM axial length & $L_{\mathrm{PM}}$ & 10 & {$[\mathrm{~mm}]$} \\
\hline
\end{tabular}

\section{B. Windage losses}

Windage losses are really important in very-high-speed machines, in the sense that they are a non-negligible part of the total losses. Indeed, they have the highest rate of increase with respect to rotational speed. Many empirical models exist [16], but it is sometimes not trivial to know which one to choose, as they all give different estimations. It turns out that, for the given geometry of the prototype, Mack's model [17] matches measurements well. This was already noted in [18] and [19].

\section{Ball bearing losses}

Ball bearing losses represent also a substantial part of the total losses. Balls friction results in energy losses, which cause an increase of the temperature. The type and quantity of lubricant play a very important role. In addition, the aging of the ball bearings, the temperature, the preload, the operating load and the unbalance of the rotor have an influence on the losses.

For ball bearings running at moderate speeds, some empirical formulae based on laboratory testing are available [20]. In these formulae, the total friction torque is given as the sum of a torque due to the applied load and a torque due to the viscous property of the lubricant. Unfortunately, for very-high-speed applications [21], [22], there is not much documentation in the 
literature, as pointed out in [23]. Thus, ball bearing losses are measured most of the time. These losses can be empirically modeled by

$$
P_{\text {Bearings }}=c_{\text {Bearings } 1} \Omega^{c_{\text {Bearings } 2}},
$$

where $\Omega$ is the mechanical speed of the rotor in $\mathrm{rad} / \mathrm{s}$ and $c_{\text {Bearings1 }}$ and $c_{\text {Bearings2 }}$ are coefficients obtained by regression.

\section{Iron losses}

Iron losses are created by time-varying magnetic fields due to currents in the winding and the rotation of the PM. The second is much more important in slotless machines. According to Jordan's model [24], iron losses due to the PM sinusoidal field can be split into hysteresis and eddy current losses. Consequently, the losses are empirically modeled by

$$
P_{\text {IronPM }}=\pi\left(r_{y o}^{2}-r_{y i}^{2}\right) L_{\mathrm{PM}} k_{f}\left(c_{\text {Iron } 1} \Omega \hat{B}_{y}^{2}+c_{\text {Iron } 2} \Omega^{2} \hat{B}_{y}^{2}\right),
$$

where $\hat{B}_{y}$ is the peak magnetic flux density in the stator yoke [11], $L_{\mathrm{PM}}$ is the axial length of the PM (assumed to be shorter than the axial length of the stator), $k_{f}$ is the stacking factor and $c_{\text {Iron1 }}$ and $c_{\text {Iron2 }}$ are coefficients obtained by regression. This model is also used in [7] for a bearingless motor. And in [25], the authors have shown that Jordan's model is more appropriated than Bertotti's [26] for wide frequency ranges.

\section{E. Winding losses}

Winding losses consist of the Joule losses due to the stator currents circulation, the skin effect that concentrates the current density on the outer border of the wires and the proximity effect resulting from perturbation in between each wire of the winding. The last two sources of losses are especially occurring when the stator electrical frequency is high. In the case of slotless machines, the PM magnetic flux density creates additional eddy current losses in the winding [6]. Therefore, the total winding losses can be obtained by

$$
P_{\text {Winding }}=\underbrace{P_{\text {Joule }}+P_{\text {Skin }}+P_{\text {Prox }}}_{\text {due to the current }}+\underbrace{P_{\text {WindingPM }}}_{\text {due to the PM }},
$$

where $P_{\text {Joule }}$ represents the conduction Joule losses, $P_{\text {Skin }}$ the skin effect losses, $P_{\text {Prox }}$ the proximity effect losses and $P_{\text {WindingPM }}$ the losses due to eddy currents induced by the PM.

Nevertheless, in slotless PM machines, the airgap magnetic field is overwhelmingly due to the permanent magnet alone. Because the magnetic field created by the stator currents is low in comparison, proximity effect losses can be most of the time neglected [4]. Given that the skin effect results in an increase of the DC resistance, Joule and skin effect losses can be combined to give

$$
P_{\text {Joule }+ \text { Skin }}=\frac{3}{2} R_{\text {ph-ph }} I_{l}^{2},
$$

where $R_{\text {ph-ph }}$ is the phase-to-phase resistance taking into account the effect of the frequency and $I_{l}$ is the RMS line current. $R_{\mathrm{ph} \text { ph }}$ is thereafter measured with an LCR meter.

Eddy current losses in the winding due to the PM field can be evaluated thanks to the following analytical model.
This model does not consider the magnetic field created by the induced currents, hence it is based on a first order vector potential equation and, as a consequence, it does not take into account the proximity effect in between the turns. This can be justified by the fact that the magnetic field created by induced currents is much lower than the PM field [27]. Besides, if the skin depth of the conductor is equal to or bigger than the dimensions of the wire, the use of the diffusion equation (second order vector potential formulation) is not necessary [28].

The model considers a single rectangular section wire as visible in Fig. 2, computes the induced current density all over its surface and then integrates this current density over a time period.

From Maxwell-Faraday equation, Ohm's law and the definition of the vector potential, respectively

$$
\vec{\nabla} \times \vec{E}=-\frac{\partial \vec{B}}{\partial t}, \text { (8) } \quad \vec{E}=\rho \vec{J}, \quad \text { (9) } \vec{\nabla} \times \vec{A}=\vec{B}
$$

with $\vec{E}$ being the electrical field, $\vec{J}$ the current density and $\rho$ the electrical resistivity of the wire, one obtains

$$
\vec{\nabla} \times\left(\rho \vec{J}+\frac{\partial \vec{A}}{\partial t}\right)=0
$$

After integration [29], it yields to

$$
\vec{J}=-\sigma\left(\vec{\nabla} V+\frac{\partial \vec{A}}{\partial t}\right)
$$

where $\sigma$ is the electric conductivity of the wire and $V$ is the electric scalar potential. Introducing $\theta=\Omega t$, the time derivative of the vector potential given by (1) is

$$
\frac{\partial A_{\delta z}(r, \varphi)}{\partial t}=-\Omega c_{\delta}\left(r+\frac{r_{y i}^{2}}{r}\right) \cos (\varphi-\Omega t) .
$$

It can be rewritten in a Cartesian coordinate system and, with the help of trigonometric identities, it becomes

$$
\frac{\partial A_{\delta z}(x, y)}{\partial t}=-\Omega c_{\delta}\left(1+\frac{r_{y i}^{2}}{x^{2}+y^{2}}\right)(x \cos (\Omega t)+y \sin (\Omega t)) \text {. }
$$

The gradient of the electric scalar potential in (12) remains to be defined. Considering the wire as an open-circuit conductor (without an external electrical potential) is to say that the surface integral of induced current density on the $x-y$ plan of the wire is equal to zero

$$
\int_{y_{w i}}^{y_{w o}} \int_{-\frac{w_{w}}{2}}^{\frac{w_{w}}{2}} \nabla V(z)+\frac{\partial A_{\delta z}(x, y)}{\partial t} \mathrm{~d} x \mathrm{~d} y=0 .
$$

Thus, the induced current density in a wire is computed as

$$
\begin{aligned}
J_{z}(x, y, t)=\sigma_{w} \Omega c_{\delta}\left(\left(1+\frac{r_{y i}^{2}}{x^{2}+y^{2}}\right)\right. & (x \cos (\Omega t)+y \sin (\Omega t)) \\
& \left.-c_{w} \sin (\Omega t)\right)
\end{aligned}
$$


with

$$
\begin{array}{r}
c_{w}=\frac{1}{w_{w} h_{w}}\left(\frac{1}{2} w_{w}\left(y_{w o}^{2}-y_{w i}^{2}\right)+2 r_{y i}^{2}\left(\frac{w_{w}}{4} \ln \frac{w_{w}^{2}+4 y_{w o}^{2}}{w_{w}^{2}+4 y_{w i}^{2}}+\right.\right. \\
\left.\left.y_{w o} \arctan \frac{w_{w}}{2 y_{w o}}-y_{w i} \arctan \frac{w_{w}}{2 y_{w i}}\right)\right),
\end{array}
$$

a constant depending on the geometry. Finally, the eddy current losses induced in the winding by the PM, per unit length and for one coil of $N_{t}$ turns, are computed by the following integral

$$
P_{\text {WindingPM }}^{\prime}=\frac{2 N_{t}}{\sigma_{w} T} \int_{0}^{T} \int_{S_{w}} J_{z}^{2}(x, y, t) \mathrm{d} S \mathrm{~d} t,
$$

where $S_{w}$ is the surface of one wire and $T$ is the time period. This equation does not have an analytical solution (at least for the surface integral) and must be computed numerically.

\section{F. Rotor losses}

Rotor losses are due to eddy currents induced by the stator magnetic field in the enclosure, the permanent magnet and possibly the shaft. These losses are usually insignificant compared to the total losses in slotless machines [4]. However, in some cases, it is important to assess them since the losses produced in the rotor are not easy to dissipate. Excessive temperature in the rotor would reduce the performance of the magnet and limit the mechanical strength of materials.

Induced currents come from space harmonics due to stator slots openings (if any), the winding distribution and the stator magnetic field on one hand, and, on the other hand, from time harmonics due to the stator currents pulse width modulation (PWM) [28]. Losses due to stator magnetic field and PWM harmonics are current dependent and thus, vary with the mechanical load [30].

The rotor losses can be computed analytically [28] or by FEM [31]. However, as demonstrated experimentally in Section IV-B, rotor losses are negligible in miniaturized slotless machines and hence have not been modeled.

\section{EXPERIMENTAL VALIDATION}

\section{A. Separation of losses}

In order to isolate the losses due to the rotation of the rotor, that is the windage losses, the ball bearing losses and the winding and iron losses due to the PM field, 4 different tests can be carried out successively. The first one is a deceleration test achieved at ambient pressure. The motor is composed of the stator $\mathrm{S} 1$ and the rotor R1. By measuring the rotational speed of the shaft over the time, thanks to a contactless laser tachometer, and, knowing the rotor inertia, one gets the sum of all losses, which is

$$
-J \frac{\mathrm{d} \Omega}{\mathrm{d} t} \Omega=P_{\text {Windage }}+P_{\text {Bearings }}+P_{\text {IronPM }}+P_{\text {WindingPM }} .
$$

The second test is identical to the first one, with the same motor (stator $\mathrm{S} 1$ and rotor $\mathrm{R} 1$ ), except that it is achieved in a vacuum chamber $(P<1 \mathrm{mbar})$ as pictured in Fig. 3. Hence, windage losses are given by the subtraction of the 2 tests.

The third test allows to evaluate the ball bearing losses. To do so, the rotor R1 is replaced by an unmagnetized rotor R2 in the stator S1. This is illustrated in Fig. 4. Evidently, the new configuration has to be driven at the rated speed by means of another motor. To this end, both machines are mounted on a very accurate XYZ-stage to guarantee an alignment as perfect as possible (see Fig. 5). Once the speed is reached, the powered motor is decoupled and the deceleration of the unmagnetized rotor can be measured. This gives the sum of windage and ball bearing losses. The ball bearing losses are therefore determined by subtracting the windage losses previously obtained.

The fourth and final test enables to measure iron losses due to the PM field. The magnetized rotor R1 is placed in a stator with non-conductive coils S2, but with the same mechanical airgap and the same surface condition on the inner side of the coils (Fig. 6). The rest of the test is identical to the previous one. By subtracting the windage and the ball bearing losses to this test, one obtains the iron losses due to the PM field. Finally, the winding losses due to the PM field are obtained by subtracting all 3 other losses to the sum of all losses given by the first test.

The advantage of a spin down test is to obtain the losses vs speed curve in one measurement (although multiple measure-

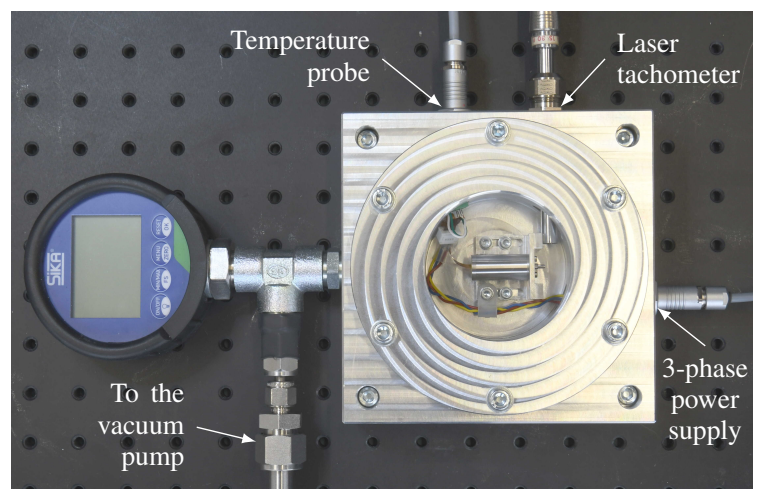

Fig. 3: Vacuum chamber $(P<1$ mbar $)$.

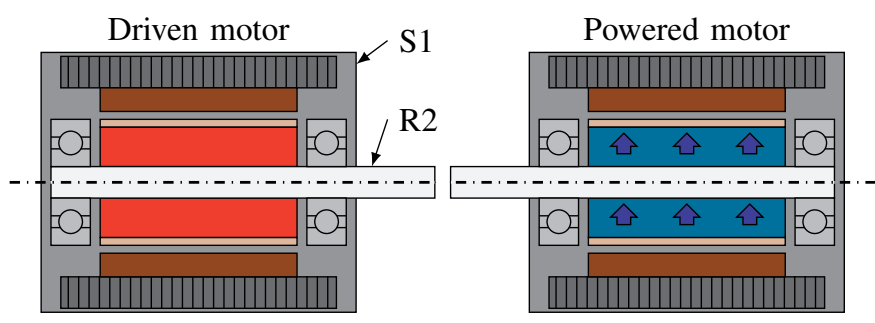

Unmagnetized PM

Stator core

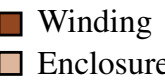

Magnet

Shaft

Fig. 4: Measurement of ball bearing losses. 


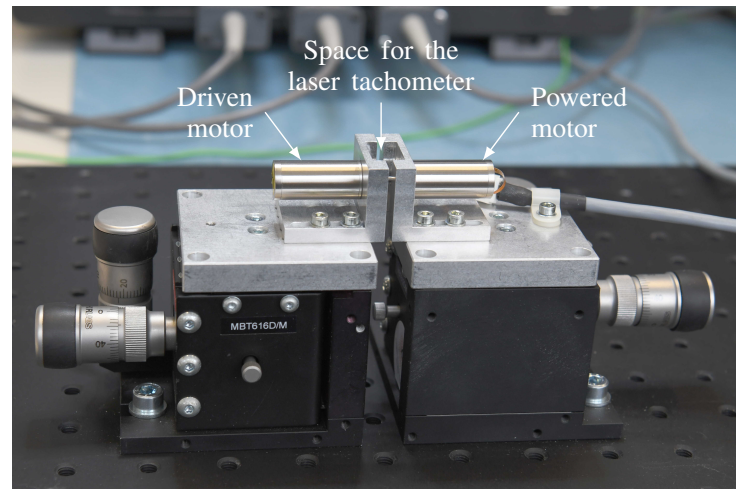

Fig. 5: Coupling bench.
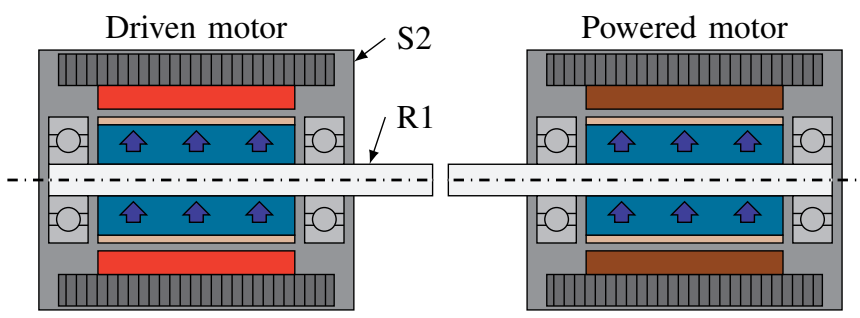

Non-conductive coils

Stator core

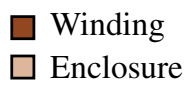

Fig. 6: Measurement of iron losses due to the PM.

ments are preferred to get an average of the tests). Mechanical measurement of the speed is preferred as opposed to back EMF frequency measurement since an unmagnetized magnet will obviously not create an induced voltage in the stator winding.

The advantage of the proposed method is to separate the losses components due to the rotation of the rotor. Hereby, the percentage of each component is known and it is possible to act to reduce some components. The disadvantage of this method is that the rotor inertia has to be known precisely and that it requires 2 different stators and 2 different rotors. Other aspects have to be carefully considered. Since these losses are temperature dependent, thermal conditions have to be the same between the setups and the measurements. The 2 stators and the 2 rotors have to be as identical as possible geometrically and mechanically. One has to be sure that the ball bearing preload and the mechanical airgap are the same. A good practice is to perform similar measurements on different setups and compare the results obtained with each other if possible.

\section{B. Results}

Every losses measurement in the following is an average of 7 to 10 measurements with the same temperature conditions between each of the 4 tests. Fig. 7 gives the 4 losses components with respect to rotational speed. Iron losses due to the PM have been measured only up to $300 \mathrm{krpm}$ (Fig. 7c) because the coupling was not able to withstand the requested torque at higher speed. Consequently, winding losses due to the PM have also been determined up to $300 \mathrm{krpm}$ only (Fig. 7d).

Fig. 7a compares the measurement of windage losses (squares) with the model given by Mack [19]. The error is $24 \%$ at $120 \mathrm{krpm}$ and then ranges from $-16.7 \%$ to $8.6 \%$ above $120 \mathrm{krpm}$, which is more than satisfactory for an empirical model. According to the Taylor number $T a$, the flow in the airgap is laminar up to $50 \mathrm{krpm}(\mathrm{Ta}=41.2)$ and so-called Taylor vortices start to appear beyond that threshold. The speed where the flow is fully turbulent $(T a>400)$ is beyond 400 krpm.

Ball bearing losses are visible in Fig. 7b. The error between the measurements and the model given by (4) ranges from $6.6 \%$ to $12.4 \%$ above $120 \mathrm{krpm}$. As for the error on iron losses due to the PM field in Fig. 7c, it ranges from $-6.6 \%$ to $11.3 \%$ above $120 \mathrm{krpm}$ between the model given by (5) and the measurements. The values obtained for the constants of (4) and (5) are given in Table II. Fig. 7c shows a linear behaviour due to hysteresis losses up to $170 \mathrm{krpm}$. Afterwards, eddy current losses become more important. Two Steinmetz's equations found in the literature [32], [33] for the computation of iron losses in Metglas ${ }^{\circledR}$ 2605SA1 are highlighted in Fig. 7c. The first one underestimates a lot the losses whereas the second one overestimates them. This demonstrates that empirical coefficients found in the literature have to be used carefully.

Winding losses due to the PM field in Fig. 7d are compared with the model described in Section III-E. The model underestimates the losses up to $-28.8 \%$ in a narrow range, close to $150 \mathrm{krpm}$, but remains excellent elsewhere.

In order to justify the extrapolation of models for the iron and winding losses due to the PM field from 300 to 400 krpm (Figs. 7c and 7d), all the losses models are summed and compared to the measurements. The matching is excellent as it can be seen in Fig. 8. Furthermore, the share of every component can be made out. It turns out that the 4 components are pretty well balanced.

By measuring no-load electrical losses between the power converter and the motor, with a high precision 3-phase power analyzer, a power balance can be achieved. The difference between no-load electrical losses and the sum of all losses due to the rotation of the rotor gives the sum of losses due to the stator currents. That is, Joule losses (including skin effect losses) and proximity effect losses in the coils, stator iron losses and induced eddy current losses in the rotor. These losses are visible in Fig. 9 where Joule losses, given by (7), are in yellow and can be separated from the rest (balance losses) in brown. The amount of the aforementioned losses at 400 $\mathrm{krpm}$ is about $4 \%$ of the total no-load losses. This confirms the hypothesis made previously that the magnetic flux density in slotless PM motors is overwhelmingly due to permanent magnets.

Back EMF voltage has been measured up to $250 \mathrm{krpm}$ as visible in Fig. 10. The value of the back EMF constant obtained by measurement is $k_{\text {emeas }}=330.5 \mu \mathrm{V} / \mathrm{rad} / \mathrm{s}$. The model described in Section III-A gives a constant of $k_{e}=$ $334.9 \mu \mathrm{V} / \mathrm{rad} / \mathrm{s}$ ( $1.3 \%$ error). 


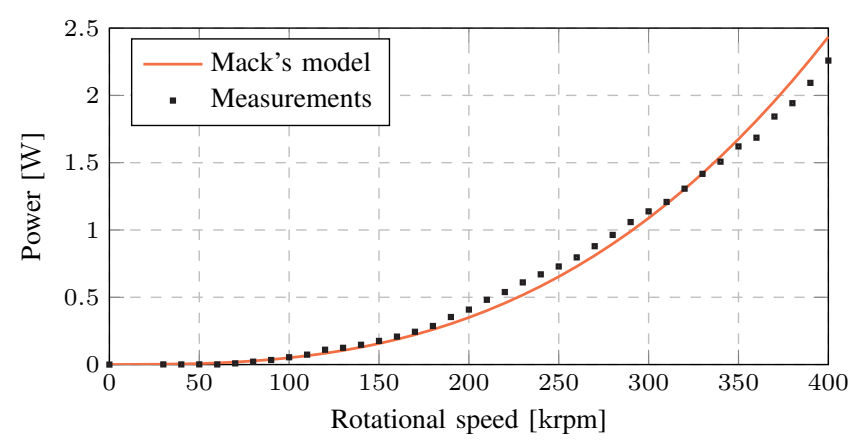

(a) Windage losses.

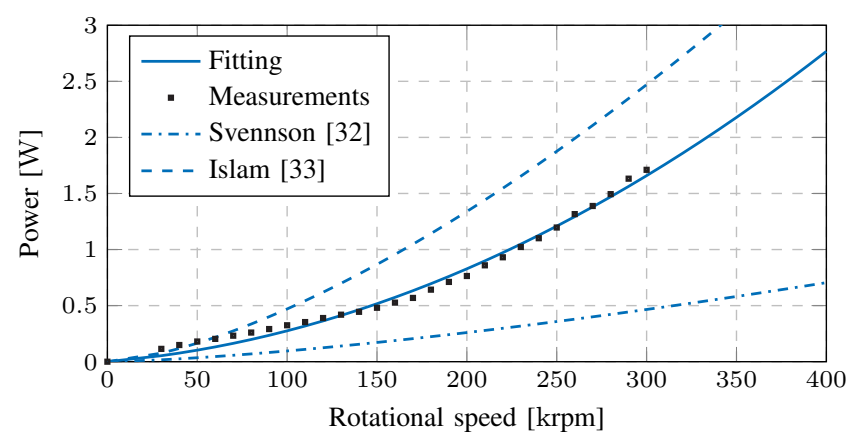

(c) Iron losses due to the PM.

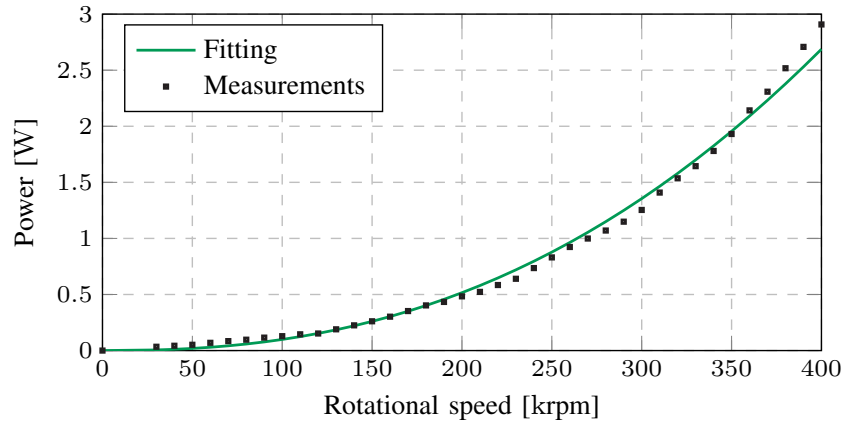

(b) Ball bearing losses.

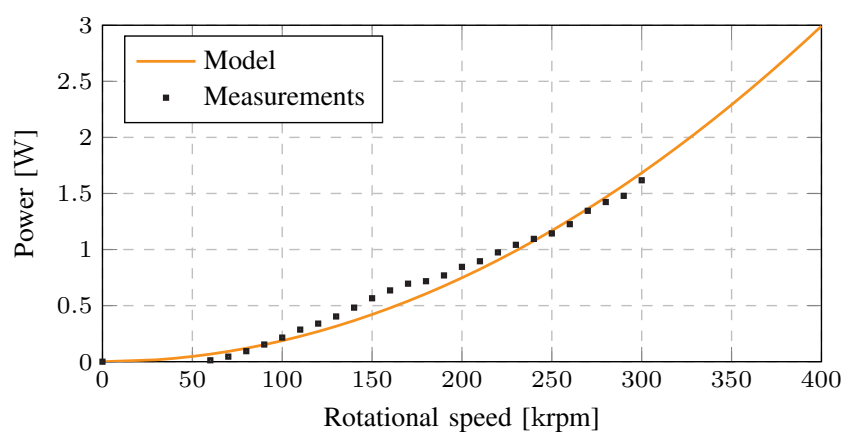

(d) Winding losses due to the PM.

Fig. 7: Measurements of losses components due to the rotation of the rotor.

\section{TABLE II: LOSSES MODELS CONSTANTS}

\begin{tabular}{|c|c|}
\hline \multicolumn{2}{|c|}{ Ball bearing losses } \\
\hline$c_{\text {Bearings1 }}$ & $26.677 \times 10^{-12}$ \\
\hline$c_{\text {Bearings2 }}$ & 2.380 \\
\hline \multicolumn{2}{|c|}{ Iron losses due to the PM } \\
\hline$c_{\text {Iron1 }}$ & 11.415 \\
\hline$c_{\text {Iron2 }}$ & $1.110 \times 10^{-3}$ \\
\hline
\end{tabular}

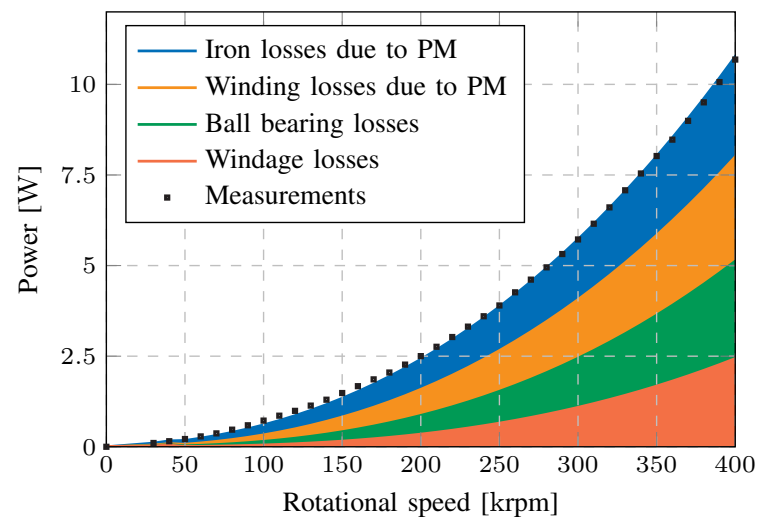

Fig. 8: Sum of all losses models vs measurements of all losses due to the rotation of the rotor.

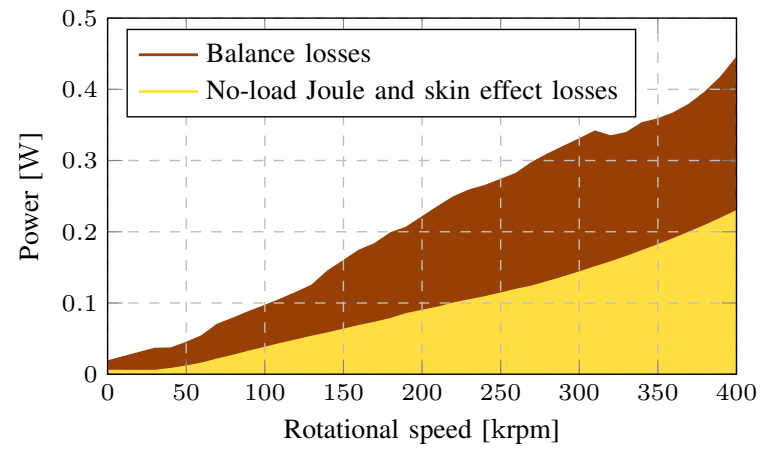

Fig. 9: Losses due to the stator currents.

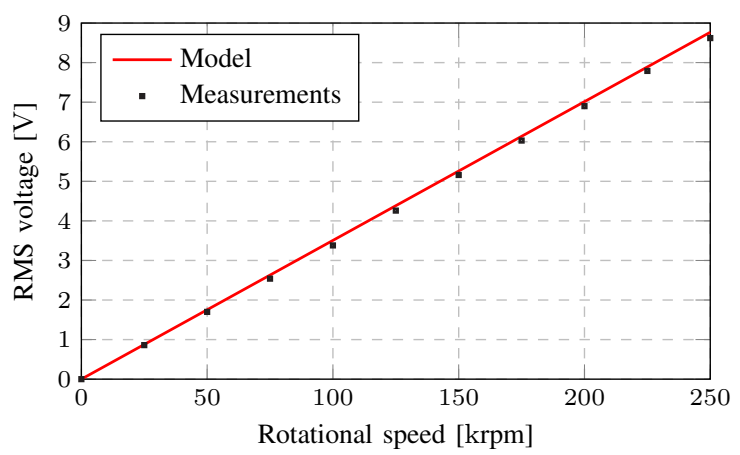

Fig. 10: Back EMF voltage vs rotational speed. 


\section{CONCLUSION}

An experimental method to separate losses components due to the rotation of the rotor in very-high-speed permanent magnet machines with ball bearings has been tested on a miniaturized motor up to $400 \mathrm{krpm}$. To the authors' knowledge it is one of the smallest and fastest electrical motor ever operated. These losses are the windage losses, the ball bearing losses and the winding and iron losses due to the rotation of the permanent magnet. Knowing the repartition of these losses allows to act on and reduce the most important of them.

Moreover, thanks to this experimental method, an analytical model for the computation of induced eddy current losses in rectangular section conductors due to a rotating magnetic field has been validated, along with an empirical windage losses model. Plus, the comparison of iron losses measurement in Metglas ${ }^{\circledR} 2605$ SA1 with other papers have highlighted the fact that losses coefficients should be used with care, as they can give really different estimations.

Finally, the paper gathers and validates all the essential models for the design of VHS slotless permanent magnet motors. This allows to have reliable and accurate losses models for the development of further motors.

\section{REFERENCES}

[1] D. Gerada, A. Mebarki, N. L. Brown, C. Gerada, A. Cavagnino, and A. Boglietti, "High-Speed Electrical Machines: Technologies, Trends, and Developments," IEEE Transactions on Industrial Electronics, vol. 61, pp. 2946-2959, June 2014.

[2] C. Zwyssig, J. Kolar, and S. Round, "Megaspeed Drive Systems: Pushing Beyond 1 Million r/min," IEEE/ASME Transactions on Mechatronics, vol. 14 , pp. 564-574, Oct. 2009.

[3] G. Burnand, D. M. Araujo, and Y. Perriard, "Very-high-speed permanent magnet motors: Mechanical rotor stresses analytical model," in IEEE International Electric Machines and Drives Conference (IEMDC), pp. 1-7, IEEE, May 2017.

[4] A. Borisavljevic, Limits, Modeling and Design of High-Speed Permanent Magnet Machines. Springer Theses, Berlin, Heidelberg: Springer Berlin Heidelberg, 2013.

[5] A. Schoppa and J. Schneider, "Influence of the manufacturing process on the magnetic properties of non-oriented electrical steels," Journal of Magnetism and Magnetic Materials, p. 5, 2000.

[6] J. Luomi, C. Zwyssig, A. Looser, and J. Kolar, "Efficiency Optimization of a 100-W 500000-r/min Permanent-Magnet Machine Including AirFriction Losses," IEEE Transactions on Industry Applications, vol. 45, pp. 1368-1377, July 2009.

[7] H. Mitterhofer, D. Andessner, and W. Amrhein, "Analytical and experimental loss examination of a high speed bearingless drive," in International Symposium on Power Electronics Power Electronics, Electrical Drives, Automation and Motion, (Sorrento, Italy), pp. 146-151, IEEE, June 2012.

[8] H. Mitterhofer, W. Gruber, and W. Amrhein, "On the High Speed Capacity of Bearingless Drives," IEEE Transactions on Industrial Electronics, vol. 61, pp. 3119-3126, June 2014.

[9] D. Steinert, I. Kovacevic-Badstubner, T. Nussbaumer, and J. W. Kolar, "Loss investigation of slotless bearingless disk drives," in 2015 IEEE Energy Conversion Congress and Exposition (ECCE), (Montreal, QC, Canada), pp. 4418-4424, IEEE, Sept. 2015.

[10] P. Puentener, M. Schuck, D. Steinert, T. Nussbaumer, and J. W. Kolar, "A 150 000-r/min Bearingless Slice Motor," IEEE/ASME Transactions on Mechatronics, vol. 23, pp. 2963-2967, Dec. 2018.

[11] G. Burnand and Y. Perriard, "Very-High-Speed Miniaturized Permanent Magnet Motors: Design and Optimization," in IEEE Energy Conversion Congress and Exposition (ECCE), (Baltimore), pp. 1-7, IEEE, Oct. 2019.

[12] N. Bianchi, S. Bolognani, and F. Luise, "Potentials and Limits of HighSpeed PM Motors," IEEE Transactions on Industry Applications, vol. 40, pp. 1570-1578, Nov. 2004.
[13] A. Borisavljevic, H. Polinder, and J. Ferreira, "On the Speed Limits of Permanent-Magnet Machines," IEEE Transactions on Industrial Electronics, vol. 57, pp. 220-227, Jan. 2010.

[14] G. Burnand, D. M. Araujo, and Y. Perriard, "Optimization of shape and topology for slotless windings in BLDC machines," in 21st International Conference on Electrical Machines and Systems (ICEMS), pp. 1-6, IEEE, Oct. 2018.

[15] P. Ragot, Modélisation analytique multiphysique pour la conception optimale de moteurs synchrones à aimants permanents. $\mathrm{PhD}$ thesis, École Polytechnique Fédérale de Lausanne, Lausanne, 2008.

[16] J. Saari, Thermal analysis of high speed induction machines. $\mathrm{PhD}$ thesis, Helsinki University of Technology, Espoo, 1998.

[17] M. Mack, Luftreibungsverluste bei elektrischen Maschinen kleiner Baugrössse. PhD thesis, Universität Stuttgart (FH), Stuttgart, 1967.

[18] J. Demierre, A. Rubino, and J. Schiffmann, "Modeling and Experimental Investigation of an Oil-Free Microcompressor-Turbine Unit for an Organic Rankine Cycle Driven Heat Pump," Journal of Engineering for Gas Turbines and Power, vol. 137, no. 3, p. 032602, 2015.

[19] G. Burnand, D. M. Araujo, C. Koechli, and Y. Perriard, "Validation by measurements of a windage losses model for very-high-speed machines," in 20th International Conference on Electrical Machines and Systems (ICEMS), pp. 1-4, IEEE, Aug. 2017.

[20] T. A. Harris and M. N. Kotzalas, Rolling bearing analysis - Essential concepts of bearing technology, vol. 1. Boca Raton, FL: CRC/Taylor \& Francis, 5th ed., 2007.

[21] B. Bossmanns and J. F. Tu, "A Power Flow Model for High Speed Motorized Spindles-Heat Generation Characterization," Journal of Manufacturing Science and Engineering, vol. 123, no. 3, p. 494, 2001.

[22] A. Zahedi and M. Movahhedy, "Thermo-mechanical modeling of high speed spindles," Scientia Iranica, vol. 19, pp. 282-293, Apr. 2012.

[23] P.-D. Pfister and Y. Perriard, "Very-high-speed slotless permanentmagnet motors: Analytical modeling, optimization, design, and torque measurement methods," IEEE Transactions on Industrial Electronics, vol. 57, pp. 296-303, Jan. 2010.

[24] A. Krings and J. Soulard, "Overview and Comparison of Iron Loss Models for Electrical Machines," Journal of Electrical Engineering, vol. 10, no. 3, pp. 162-169, 2010.

[25] J. Juergens, B. Ponick, O. Winter, and A. Fricasse, "Influences of iron loss coefficients estimation on the prediction of iron losses for variable speed motors," in 2015 IEEE International Electric Machines \& Drives Conference (IEMDC), (Coeur d'Alene, ID), pp. 1254-1259, IEEE, May 2015.

[26] G. Bertotti, F. Fiorillo, and G. P. Soardo, "The Prediction Of Power Losses In Soft Magnetic Materials," Le Journal de Physique Colloques, vol. 49, pp. C8-1915-C8-1919, Dec. 1988.

[27] G. Francois, F. Baudart, F. Henrotte, and B. Dehez, "Numerical Investigation of Eddy Current Losses in Airgap PCB Windings of Slotless BLDC Motors," in 21 st International Conference on Electrical Machines and Systems (ICEMS), pp. 1-7, IEEE, Oct. 2018.

[28] Z. Zhu, K. Ng, N. Schofield, and D. Howe, "Improved analytical modelling of rotor eddy current loss in brushless machines equipped with surface-mounted permanent magnets," IEEE Proceedings - Electric Power Applications, vol. 151, no. 6, p. 641, 2004.

[29] J. A. Tegopoulos and E. E. Kriezis, Eddy currents in linear conducting media, vol. 16 of Studies in electrical and electronic engineering. Amsterdam ; New York: Elsevier, 1985.

[30] C. Huynh, L. Zheng, and D. Acharya, "Losses in High Speed Permanent Magnet Machines Used in Microturbine Applications," Journal of Engineering for Gas Turbines and Power, vol. 131, no. 2, p. 022301, 2009.

[31] Jiabin Wang, K. Atallah, R. Chin, W. M. Arshad, and H. Lendenmann, "Rotor Eddy-Current Loss in Permanent-Magnet Brushless AC Machines," IEEE Transactions on Magnetics, vol. 46, pp. 2701-2707, July 2010.

[32] L. Svensson, K. Frogner, P. Jeppsson, T. Cedell, and M. Andersson, "Soft magnetic moldable composites: Properties and applications," Journal of Magnetism and Magnetic Materials, vol. 324, pp. 2717-2722, Sept. 2012.

[33] M. R. Islam, Y. Guo, and J. Zhu, "A High-Frequency Link Multilevel Cascaded Medium-Voltage Converter for Direct Grid Integration of Renewable Energy Systems," IEEE Transactions on Power Electronics, vol. 29, pp. 4167-4182, Aug. 2014. 